\title{
Adenoviral expression of a transforming growth factor- $\beta$ I antisense mRNA is effective in preventing liver fibrosis in bile-duct ligated rats Monica Arias ${ }^{1}$, Sibille Sauer-Lehnen ${ }^{1}$, Jens Treptau ${ }^{1}$, Nora Janoschek ${ }^{1}$, Ingo Theuerkauf ${ }^{2}$, Reinhard Buettner ${ }^{2}$, Axel M Gressner ${ }^{1}$ and Ralf Weiskirchen*1
}

Address: ${ }^{1}$ Institute of Clinical Chemistry and Pathobiochemistry, RWTH-University Hospital, Aachen, D-52074, Germany and ${ }^{2}$ Institute of Pathology, University Bonn, D-53127, Germany

Email: Monica Arias - pkuhn@web.de; Sibille Sauer-Lehnen - rweiskirchen@post.klinikum.rwth-aachen.de; Jens Treptau - jens.treptau@post.rwth-aachen.de; Nora Janoschek - njanoschek@ukaachen.de; Ingo Theuerkauf - ingo.theuerkauf@ukb.unibonn.de; Reinhard Buettner - reinhard.buettner@mailer.uniklinik-bonn.de; Axel M Gressner - gressner@ukaachen.de;

Ralf Weiskirchen* - rweiskirchen@ukaachen.de

* Corresponding author

Published: 18 October 2003

BMC Gastroenterology 2003, 3:29
Received: 14 July 2003

Accepted: 18 October 2003

This article is available from: http://www.biomedcentral.com/I47I-230X/3/29

(C) 2003 Arias et al; licensee BioMed Central Ltd. This is an Open Access article: verbatim copying and redistribution of this article are permitted in all media for any purpose, provided this notice is preserved along with the article's original URL.

\begin{abstract}
Background: Transforming growth factor- $\beta$ (TGF- $\beta$ ) is a key mediator in establishing liver fibrosis. Therefore, TGF- $\beta$ as a causative agent may serve as a primary target for antifibrotic gene therapy approaches. We have previously shown that the adenoviral delivery of a transgene constitutively expressing a TGF- $\beta$ I antisense mRNA blocks TGF- $\beta$ synthesis in culture-activated hepatic stellate cells and effectively abolishes ongoing fibrogenesis in vitro.
\end{abstract}

Methods: Ligature of the common bile duct was used to induce liver fibrosis in rats. The effect of the TGF- $\beta$ I antisense on fibrogenesis was analyzed in this model of liver injury.

Results: In the present study, we demonstrate that the adenoviral vector directs the synthesis of mRNA quantities that are approximately 8000 -fold more abundant than endogenous TGF- $\beta$ I mRNA. In experimentally injured rat livers induced by ligature of the common bile duct, a model for persistent fibrogenesis and cirrhosis, administration of the adenoviral vector abrogates TGF- $\beta$ enhanced production of collagen and $\alpha$-smooth muscle actin. Furthermore, the number of cells positive for $\alpha$-smooth muscle actin resulting from active recruitment of activated hepatic stellate cells around the bile ductular structures was significantly reduced in animals after application of Ad5-CMV-AS-TGF- $\beta$ I. However, the observed elevated serum levels of aspartate aminotransferase, alanine aminotransferase, and bilirubin induced in this obstructive liver injury model were not significantly altered in the presence of the TGF- $\beta$ antagonist.

Conclusion: Taken together, our data provides in vivo evidence that the delivery of TGF- $\beta$ I antisense mRNA specifically abolishes the diverse effects of direct TGF- $\beta$ function in ongoing liver fibrogenesis. Therefore, we conclude that the expressed transgene is therapeutically useful for inhibition of TGF- $\beta$ effects in diverse applications, ranging from clarification of TGF- $\beta$ function in the course of liver injury to the development of novel gene therapeutic approaches. 


\section{Background}

Transforming growth factor- $\beta 1$ (TGF- $\beta 1$ ) is a multifunctional cytokine involved in the regulation of cell proliferation, differentiation, extracellular matrix production, wound healing and tissue repair [1]. In liver fibrogenesis, TGF- $\beta$ is of crucial importance triggering excessive formation and deposition of connective tissue matrix molecules [2]. Typically, during hepatic injury resting hepatic stellate cells (HSC) undergo cellular activation which in term is associated with proliferation, increased contractile activity, fibrogenesis, changes in matrix protease activity, loss of intracellular retinoid storage, production of cytokines, and phenotypic transformation to a myofibroblast-like morphology [3]. TGF- $\beta$ binds and signals through distinct heteromeric transmembrane receptors, including type I (T $\beta R I)$ and type II (TRRII) serine/threonine kinase receptors [4]. Activation of this complex is initiated by binding of TGF- $\beta$ to T $\beta$ R-II triggering heteromerization with and transphosphorylation of T $\beta \mathrm{RI}$. The signal is then propagated through phosphorylation of receptor associated Smad 2 and 3 and oligomerization with the common mediator Smad4. Complexes of phosphorylated Smad2 or 3 and Smad4 translocate into the nucleus, where they affect transcription of target genes via direct DNA binding or by association with numerous DNA binding proteins $[5,6]$. Aberrant expression of TGF- $\beta$ is involved in a number of disease processes, including fibrosis and inflammation. This is demonstrated in transgenic mice, which develop multiple tissue lesions including hepatic fibrosis as a consequence of elevated levels of TGF- $\beta$ [79]. This evidence provides a rationale for targeting TGF- $\beta$ as an antifibrotic agent. In the last decade, significant advances in cell biology have opened several ways to inhibit TGF- $\beta$ action. One experimental approach to block TGF- $\beta$ signaling is the local expression of a soluble, dominant negative TRRII [10]. During liver injury, this strategy is appropriate to prevent progression of fibrosis, to inhibit matrix synthesis and to decrease cell proliferation [11-13] indicating that prevention of fibrosis through anti-TGF- $\beta$ treatment could have some future therapeutic value. Treatment with short DNA antisense oligonucleotides was shown to suppress TGF- $\beta 1$ function in an interstitial fibrosis model and in balloon catheter injury $[14,15]$. Impressively, overexpression of antagonistic Smad7, a natural antagonist of TGF- $\beta$ signaling was sufficient to prevent bleomycin-induced pulmonary fibrosis in mice [16].

We have recently demonstrated that adenoviral delivery of an antisense RNA complementary to the 3' coding sequence of rat TGF- $\beta 1$ is able to suppress the synthesis of TGF- $\beta 1$ in culture-activated rat HSC [17]. The adenoviral vehicle directs high-level expression of the transgene and the transduced antisense was found to block TGF- $\beta$ synthesis as assessed by immunoprecipitation, western blot analysis, quantitative TGF- $\beta 1$ ELISA, and cell proliferation assays. Moreover, we found that the construct was able to induce differential activity of TGF- $\beta 1$ responsive genes indicating that the delivery of this mRNA, complementary to endogenous TGF- $\beta$ transcript, offers a feasible approach to block TGF- $\beta 1$ signaling in this experimental in vitro model for liver fibrogenesis [17].

In the present study, we demonstrate that infection with Ad5-CMV-AS-TGF- $\beta 1$ induces cellular mRNA quantities that are approximately 8000 -fold abundant over endogenous TGF- $\beta 1$ mRNA. In rats with ligature of the common bile duct (BDL), an experimental model of liver fibrogenesis, the administration of the adenoviral vector abrogates the production of collagen and $\alpha$-smooth muscle actin ( $\alpha$ SMA) but has no significant impact on serum levels of aspartate aminotransferase (AST), alanine aminotransferase (ALT), or bilirubin. Taken together, our data gives evidence that the transfer of the TGF- $\beta 1$ antisense is sufficient to specifically abolish ongoing liver fibrogenesis but does not interfere with the injury per se.

\section{Methods}

\section{Isolation and culture of liver cells}

Hepatic stellate cells (HSC) were isolated from male Sprague-Dawley rats following a standard procedure with slight modifications $[18,19]$. Briefly, livers were perfused with pronase and collagenase and the resulting cell suspensions were filtered through a nylon mesh, centrifuged and washed in ice cold Hanks buffered standard saline (HBSS; PAA Laboratories GmbH, Linz, Austria) containing $0.25 \%(\mathrm{w} / \mathrm{v})$ BSA. HSC were further purified by a single-step density gradient centrifugation with $8.25 \%(\mathrm{w} / \mathrm{v})$ Nycodenz $^{\circledast}$ (Nycomed Pharma, Oslo, Norway) as described in detail elsewhere $[20,21]$ and seeded in Dulbeccos's modified Eagle medium (DMEM; Bio Whittaker Europe, Verviers, Belgium) supplemented with $10 \%(\mathrm{v} / \mathrm{v})$ fetal calf serum (FCS; Seromed, Biochrom KG, Berlin, Germany), and $4 \mathrm{mM}$ L-glutamine (ICN Biomedicals Inc., Aurora, Ohio). Additionally, the culture medium was supplemented with penicillin $(100 \mathrm{IU} / \mathrm{ml})$ and streptomycin $(100 \mu \mathrm{g} / \mathrm{ml})$.

\section{RNA isolation and northern blot analysis}

Isolation and Northern blot analysis of total cellular RNA from HSC was carried out as described previously [19]. Briefly, equal amounts $(5 \mu \mathrm{g})$ of total RNA were separated by electrophoresis on a $1.2 \%(\mathrm{w} / \mathrm{v})$ denaturing agarose gel, transferred to a Hybond- $\mathrm{N}$ membrane (Amersham Pharmacia, Braunschweig, Germany), and fixed by baking for 2 hours at $80^{\circ} \mathrm{C}$. Blots were hybridized with [ $\left.\alpha-32 \mathrm{P}\right]$ dCTP-labeled random primed probes (Amersham) and autoradiographs were exposed to Kodak X-OMAT AR films using intensifying screens. As an internal standard for equal gel loading the blots were re-hybridized with a 
cDNA specific for glyceraldehyde-3-phosphate dehydrogenase $(G A P D H)$.

\section{SDS-polyacrylamide gel electrophoresis (SDS-PAGE) and immunoblotting}

Whole cell protein extracts were prepared in RIPA buffer [20 mM Tris-HCl (pH 7.2), $0.15 \mathrm{M} \mathrm{NaCl}, 2 \%$ (v/v) NP-40, $0.1 \%(\mathrm{w} / \mathrm{v})$ SDS, $0.5 \%$ sodium deoxycholate] and concentrations were quantified using the Micro BCA protein assay reagent kit (Pierce, Rockford, IL). Equal amounts of protein were resolved by reducing SDS-PAGE (Novex, Groningen, The Netherlands). For immunoblotting, proteins were electroblotted onto nitrocellulose membranes. Membrane blocking and incubation with antibodies were performed as described previously [17]. $\alpha$-SMA was detected with the monoclonal mouse antibody clone asm-1 (Roche Diagnostics, Mannheim, Germany) followed by incubation with horseradish peroxidase (HRP)conjugated anti-mouse IgG (Santa Cruz Biotech., Santa Cruz, CA) and the supersignal chemiluminescent substrate (Pierce).

\section{Adenoviral vector construction and virus purification}

The recombinant E1-deleted adenoviral vectors constitutively expressing the enhanced green fluorescent protein (EGFP) or rat antisense TGF- $\beta 1$ were generated as described previously $[17,22]$. Adenoviral particles were purified by a standard $\mathrm{CsCl}$ density protocol followed by a membrane based ion exchange chromatography for purification of adenoviral particles (BD Bioscience, CLONTECH, Palo Alto, CA). Adenoviral titers were spectrometrically determined and appropriate aliquots were stored at $-80^{\circ} \mathrm{C}$ until use.

\section{Experimental model of liver fibrosis}

Male Sprague-Dawley rats $(245.6 \pm 10.8 \mathrm{~g})$ were injected twice (at day 0 and day 7) with recombinant adenoviruses $\left(1 \times 10^{10} \mathrm{pfu} / \mathrm{kg}\right)$ or phosphate buffered saline via the tail vein. At day two, the common bile ducts were double ligated under halothane anesthesia. Rats were sacrificed after 12 days, and pieces of the livers were fixed in $10 \%$ formalin for histological examination or frozen immediately in liquid nitrogen and stored at $-80^{\circ} \mathrm{C}$ for RNA isolation. Measurements of AST, ALT, and bilirubin were performed from blood samples following standard protocols. The study as presented is in compliance with the German Animal Protection Act, and was approved by the local committee for care and use of laboratory animals at the RWTH-University Hospital. Experiments applying adenoviral constructs to cells or animals are covered by permission of the Landesumweltamt Nordrhein-Westfalen (Az. 521-K-1.59/99).

\section{Histological scoring of liver fibrosis in rats}

Morphological evaluation of induced liver fibrogenesis was performed using the semi-quantitative fibrotic focus score proposed for staging and grading of histopathological lesion of chronic hepatitis in humans [23]. Briefly, pieces of left liver lobules were fixed in $10 \%$ formalin and stained with hematoxylin/eosine for identification of lesions. In the stained sections, the lesions were defined as follows: absence of lesions $=0$; occasional small localized lesions with fibrous expansion of some portal areas $=1$; thickening of liver septa with fibrous expansion of most portal areas $=2$; and thickened continuous fibrous areas with periportal rounding and occasional portal to portal bridging $=3$. The liver sections were coded and independently examined in a blinded manner by two different pathologists.

\section{Immunohistochemistry}

Liver tissues were fixed in $4 \%$ paraformaldehyde and embedded in paraffin and $1.5-\mu \mathrm{m}$ sections were prepared. For immunohistochemistry, the sections were treated with xylene and rehydrated with decreasing graded ethanol washes. For $\alpha$-SMA staining, the slides were treated with a polyclonal anti-rat $\alpha$-SMA (Roche Diagnostics) followed by HRP-conjugated secondary anti-rabbit antibody (DAKO, Hamburg, Germany). $\alpha$-SMA staining was detected using the DAB substrate (Vector Laboratories, Burlingame, CA) and sections were counterstained with eosine.

\section{Sirius red staining}

Collagen staining was performed as described previously [24]. Briefly, liver sections were deparaffinized and the slides were incubated for $30 \mathrm{~min}$ in a solution of saturated picric acid containing $0.1 \%$ direct red 80 and $0.1 \%$ Fast Green FCF. Stained slides were washed in running distilled water, dehydrated, mounted, and examined by light microscopy.

\section{Quantitative real-time PCR}

Total RNA $(2 \mu \mathrm{g})$ isolated from untreated HSC, and HSC infected with Ad5-CMV-EGFP or Ad5-CMV-AS-TGF- $\beta 1$ was reversed transcribed in $20 \mu \mathrm{l}$ using the SuperscriptII Reverse Transcriptase (Invitrogen, Karlsruhe, Germany) and random hexamer primer according to the manufacturer's instructions. 2- $\mu$ l aliquots of first strand cDNA samples were subjected to PCR in a volume of $20 \mu \mathrm{l}$ using $2 \mu \mathrm{M}$ forward and reverse primer, $2 \mu \mathrm{l}$ dNTPs (each 10 mM dATP, dCTP, dGTP, dTTP), 1x PCR reaction buffer, and 2.5 U Taq DNA polymerase (Roche Diagnostics). All PCR-assays were conducted in capillaries on a LightCycler system (20 $\mu$ l-reaction volume) using the LC-FastStart DNA Master SYBR Green I kit (Roche Diagnostics). Conditions were: $95^{\circ} \mathrm{C}$ for $10 \mathrm{~min}$ (initial denaturation), $95^{\circ} \mathrm{C}$ for $10 \mathrm{~s}, 66^{\circ} \mathrm{C}$ for $5 \mathrm{~s}, 72^{\circ} \mathrm{C}$ for $15 \mathrm{~s}$ ( 45 cycles) and 
$72^{\circ} \mathrm{C}$ for $1 \mathrm{~min}$ (final extension). Primer P1 [5'-d-(TGG CGT TAC CTT GGT AAC C)-3'] and P2 [5'-d(GGT GTT GAG CCC TTT CCA G)-3'] directed the amplification of a 277 -bp fragment of endogenous TGF- $\beta 1$. The same PCR conditions with primer P3 [5'-d(CAA GGT CCT TGC CCT CTA)-3'] and P4 [5'-d(GCG CAC AAT CAT GTT GGA CA)$3^{\prime}$ ] annealing to both endogenous TGF- $\beta 1$ and antisense TGF- $\beta 1$ were taken to amplify a 145 -bp fragment. For amplification of AS-TGF- $\beta 1$ specific transcripts we used primer P5 [5'-d(CGG TGA TGC GGA AGC ACC CG)-3'] and P6 [5'-d(CCT CTA CAA ATG TGG TAT GG)-3'] directing the amplification of a hybrid amplicon containing sequences specific for TGF- $\beta 1$ and the downstream SV40polyadenylation signal. After PCR, products were melted in a temperature transition procedure from $65^{\circ} \mathrm{C}$ to $95^{\circ} \mathrm{C}$ in steps of $0.1^{\circ} \mathrm{C} / \mathrm{s}$ and fluorescence signals were measured and plotted online against the temperature. The second derivative maximum method was taken to determine the crossing points automatically for individual samples and relative amounts of target gene was calculated based on the crossing point analysis (LC-software, version 5.32).

\section{Results \\ High-level expression and antifibrotic capacity of the antisense TGF- $\beta$ I device}

We cloned the adenoviral construct Ad5-CMV-AS-TGF- $\beta 1$ expressing an antisense (AS) complementary to the 3'portion of rat TGF- $\beta 1$ mRNA and a control virus expressing EGFP $[17,22]$. Both transgenes are driven by the human cytomegalovirus (CMV) immediate-early gene 1 enhancer/promoter and are fused to the SV40 early mRNA polyadenylation signal (Fig. 1A). In culture-activated HSC, Ad5-CMV-AS-TGF- $\beta 1$ is able to direct high-level expression of the antisense mRNA (Fig. 1B, top). In agreement with the functionality of the transgene the level of col $\alpha 1$ (I) mRNA, a classical marker of fibrosis, was significantly reduced in transdifferentiating HSC infected with the transgene (Fig. 1B, middle). The reduction of col $\alpha 1(\mathrm{I})$ mRNA was specific for the expressed transgene and was not observed in cells infected with other recombinant adenoviruses. To assess the relative abundance of the expressed AS-mRNA over endogenous TGF- $\beta 1$ transcripts we established SYBR Green I-based real-time quantitative PCR procedures. The assays were conducted on a LightCycler (LC) and amplification of transcripts for TGF- $\beta$ or both, TGF- $\beta$ - and AS-TGF- $\beta$, were performed by specific primer combinations (Fig. 1C). Compared to mock- or control virus-infected cells, the obtained fluorescent signals were higher in HSC infected with Ad5-CMV-AS-TGF$\beta 1$. Typically, the logarithmic amplification phase in samples taken from these cells were reached two cycles earlier suggesting that endogenous TGF- $\beta$ transcripts were approximately four fold more abundant in these cells (Fig. 1D). This finding is consistent with our previous observation that the endogenous TGF- $\beta 1$ mRNA is stabi- lized by the transgene most likely because under cellular environment mRNA/mRNA hybrids are resistant to the attack of ribonuclease $\mathrm{H}$, the key enzyme of ribonucleic acid degradation. Simultaneous amplification of both transcripts (TGF- $\beta$ and AS-TGF- $\beta$ ) revealed that equal fluorescent signals were obtained approximately 13 cycles earlier in samples of Ad5-CMV-AS-TGF- $\beta 1$-infected cells than in the controls (untreated HSC or HSC infected with Ad5-CMV-EGFP). Provided that the PCR efficiencies during the logarithmic amplification phases in each probe equals two, this points to an 8000 -fold excess of the ASmRNA relative to endogenous TGF- $\beta 1$ mRNA in these cells. With the knowledge about the high abundance of the antisense and the recent demonstration that the transgene is able to block synthesis of TGF- $\beta 1$ in vitro [17], we next asked whether the transgene is useful for the treatment of hepatic fibrosis.

\section{Ligature of the common bile buct induces fibrosis in rat}

Hepatic fibrosis in rats can be experimentally induced by double ligature of the common bile duct (BDL) for several weeks or months resulting in morphological changes in liver tissue comparable to those seen in human biliary fibrosis [25-27]. Since the first reports of this experimental model for liver injury it has been used in many laboratories to study the cellular and biological changes during liver fibrogenesis. The prolonged bile duct obstruction has many advantages over the experimentally induced cirrhosis generated by multiple doses of the $\mathrm{CCl}_{4}$ or dimethylnitrosamine (DMN), because the individual response of animals to these hepatoxins is variable, the mortality is high, and it takes a relatively long time to produce persistent fibrosis or cirrhosis. However, to validate new therapeutic strategies in this obstructive model and to allow reproducibility between different laboratories it is necessary to follow standard operating procedures. In our laboratory we use male rats of the Sprague-Dawley strain weighed approximately $250 \mathrm{~g}$ that are fed with a standard chow and having free access to trap water. Surgeries for ligature of the common bile duct are performed under deep Ketamin-Rompun anesthesia. Following our protocol, the abdominal wall of the animals is first shaved and the abdomen is cut with a scalpel through a median line (Fig. $2 \mathrm{~A}$ ). Then, the abdominal cavity is opened, and selvages are stretched and fixed with two sterile high-grade steel tweezers (Fig. 2B). Afterwards, the liver lobules are turned down and intestines are carefully pulled out to uncover the bile duct (Fig. 2C). The extrahepatic common bile duct is pulled out, fixed with forceps, and obstructed with a piece of string (Fig. 2D). A second ligature is introduced in a distance of approximately $1 \mathrm{~cm}$ (Fig. 2E). Liver is replaced into its correct position within the abdominal cavity and the abdomen is closed with sutures (Fig. 2F). Sham-operated rats are treated in the same manner except that the bile duct is not ligated. After 12 days, tremendous 


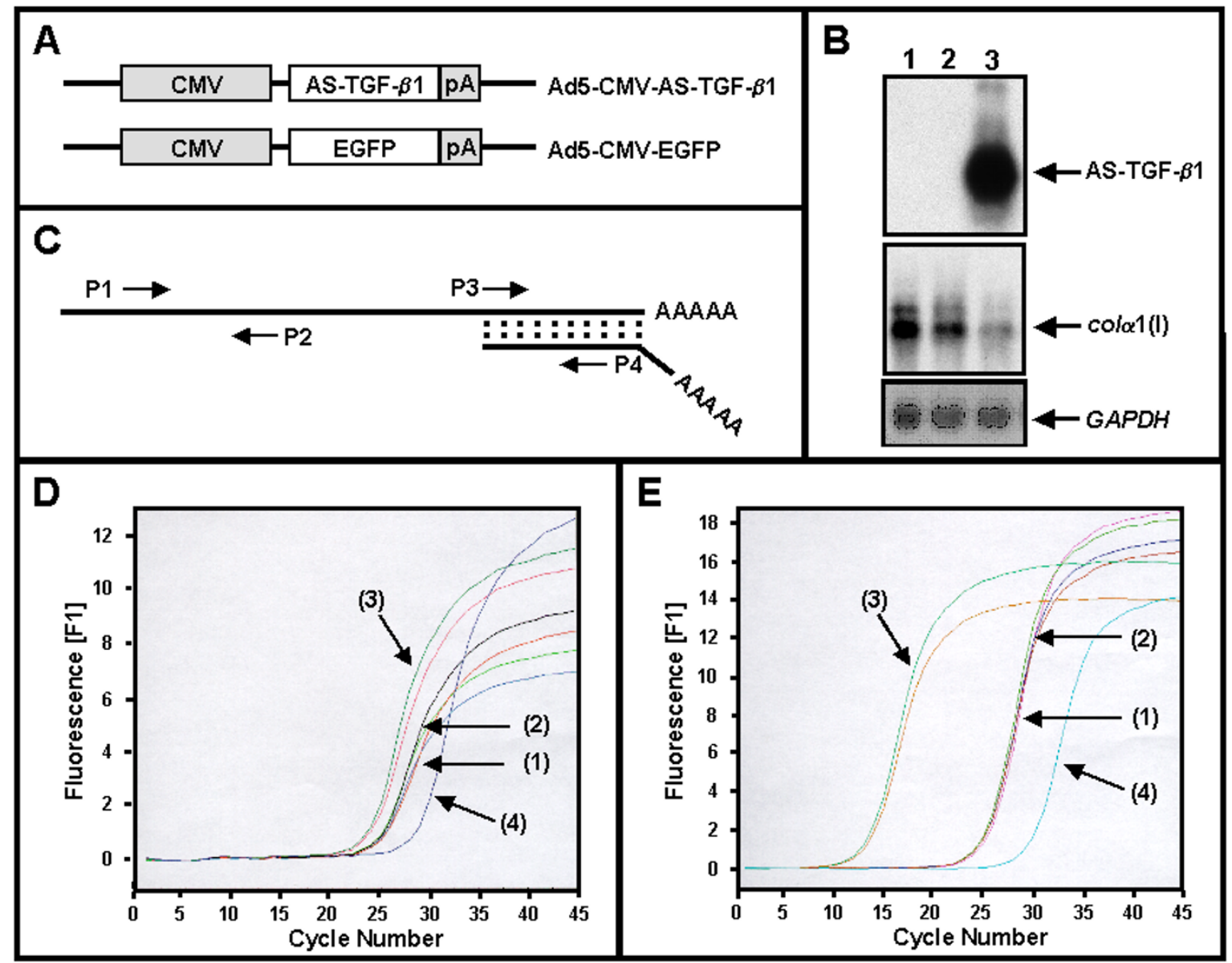

Figure I

Adenoviral expression and antifibrotic capacity of an AS-TGF- $\beta$ I mRNA in culture-activated HSC. (A) Schematic representation of Ad5-CMV-AS-TGF- $\beta$ I [17] and Ad5-CMV-EGFP [22] expressing their transgene under regulatory control of the human cytomegalovirus immediate-early gene I promoter (CMV). A SV40 polyadenylation signal (pA) downstream of each transgene directs the proper processing of the 3' end of the corresponding mRNA. (B) Northern blot analysis from untreated HSC (1), and HSC infected with Ad5-CMV-EGFP (2) or Ad5-CMV-AS-TGF- $\beta$ I (3). The blot was subsequently hybridized with ${ }^{32}$ P-labelled probes specific for TGF- $\beta I$, col $\alpha I(I)$, and GAPDH. (C) Strategy for relative quantification of transcripts specific for TGF- $\beta$ I or AS-TGF- $\beta$ I. Primer PI and P2 specific for endogenous TGF- $\beta$ I, or primer P3 and P4 specific for both, endogenous TGF- $\beta$ I and AS-TGF- $\beta$ I, were used in RT-PCR. The assay was conducted in a LightCycler system. (D, E) RNA isolated from untreated HSC (I), and HSC infected with Ad5-CMV-EGFP (2) or Ad5-CMV-AS-TGF- $\beta$ I (3) was assayed in duplicate for endogenous TGF- $\beta$ I transcripts (D) or alternatively for TGF- $\beta$ I and AS-TGF- $\beta$ I (E) using primer combinations PI and P2 (D) or P3 and P4 (E), respectively. Note, that small amounts of artificially synthesized DNA at higher cycle numbers occurring in the no-template control are due to primer dimer formation (4).

differences between sham-operated and BDL-ligated rats in regard to their liver appearance are obvious (compare Figs. 2G, 2H). In general, the obstruction induces bile duct proliferation and inflammatory/fibrotic reactions with concomitant formation of oedema and fibrotic nodules on the surface of corresponding livers. To monitor ongo- ing fibrogenesis we routinely determine the concentrations of bilirubin, and the activities of serum AST and ALT from blood samples aspirated from the tail vein. In normal controls $(n=65)$ levels for individual parameters were measured as $0.14 \pm 0.05 \mathrm{mg} / \mathrm{dl}$ (bilirubin), $53.49 \pm$ $17.31 \mathrm{U} / \mathrm{l}(\mathrm{AST})$, and $28.18 \pm 7.84 \mathrm{U} / \mathrm{l}$ (ALT), respectively 

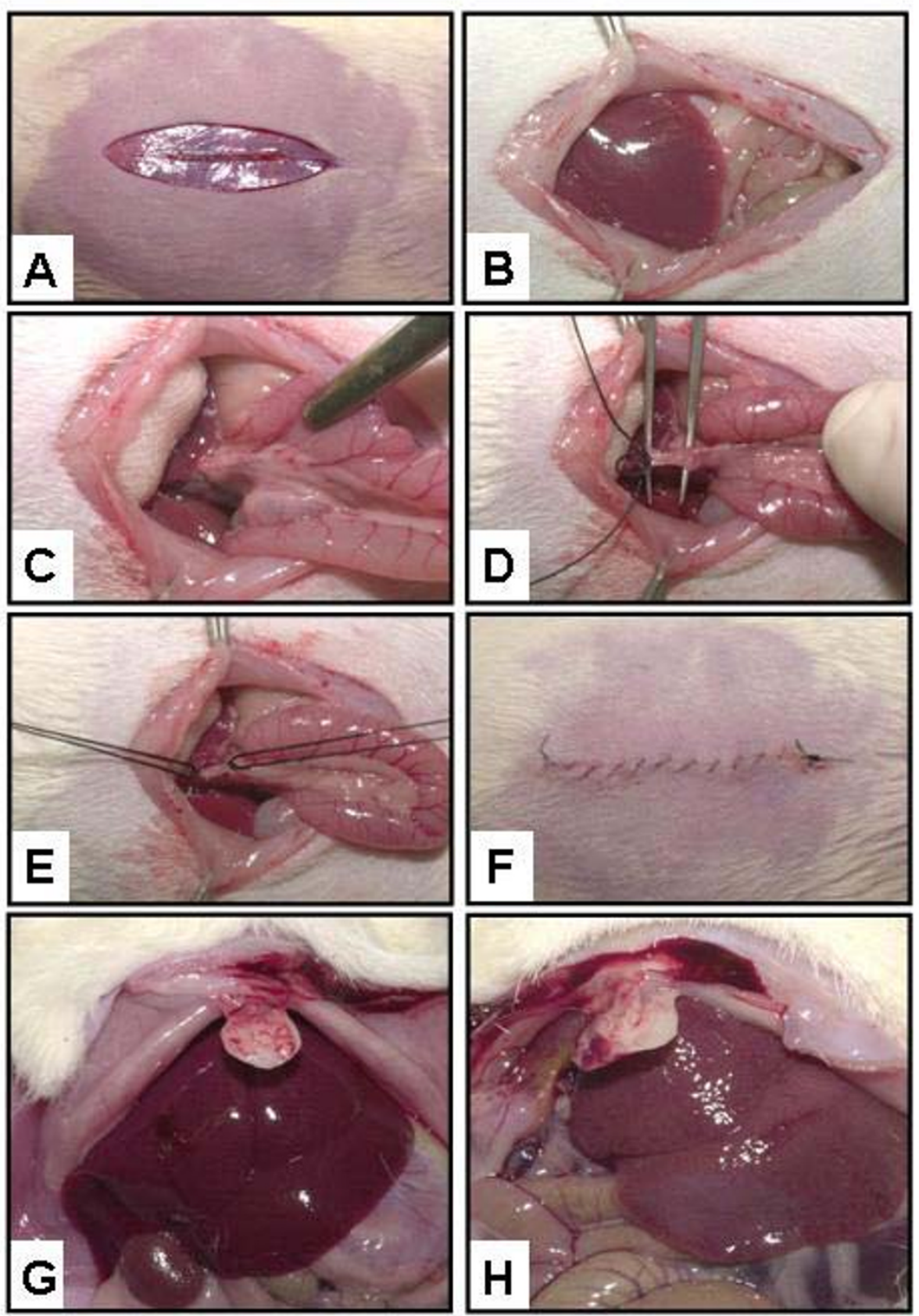

\section{Figure 2}

Double ligature model of the common bile duct in male rats of the Sprague-Dawley strain. (A) Under deep Ketamine-Rompun anesthesia the abdominal wall was shaved and a small incision with a scalpel was made. (B) The abdominal cavity was opened, and selvages were stretched and fixated with two sterile high-grade steel tweezers. (C) Liver lobules were turned down and intestines were carefully pulled out. (D) The common bile duct was fixed with forceps and obstructed with a piece of string. (E) A second ligature was set in a distance of approximately $I \mathrm{~cm}$. (F) Intestines were into the abdominal cavity and the incision was replaced/sewn by several pinpricks. (G) The livers of sham-operated animals showed no sign of fibrosis at day 12 after surgery. $(\mathbf{H})$ In contrast, in livers of animals receiving bile duct ligature a high degree of hepatic fibrosis is induced. Signs of ongoing liver fibrogenesis are the formation of oedema and fibrotic nodules on the surface of corresponding livers. 
(mean $\pm \mathrm{SD})$. In the course of obstructive cholestasis, the values of individual animals were highest at day 2 after ligature and were still increased by factors of approximately 100 (bilirubin), 6 (AST), and 5 (ALT) at day 12 compared to sham-operated controls.

\section{Gene transfer of the antisense construct directed against TGF- $\beta$ I prevents liver fibrosis in the common bile duct ligature model}

Recent reports describe that the transduction efficiency by adenoviral mediated gene transfer is strongly reduced after liver injury, but remained significant $[28,29]$. Therefore, we decided to administrate the adenoviruses two days prior setting of the injury followed by a booster injection at day 7 (5 days after BDL surgery). For histology, blood sampling, and RNA/protein extraction animals were sacrificed at day 14 corresponding to day 12 after surgery (Fig. 3A). As documented in previous studies, the administration of adenoviruses is an effective means to direct transgene expression in liver as assessed by visual detection of transduced EGFP under UV-light (not shown). However, compared to normal controls, transgene expression as assessed by delivery of an EGFPreporter was drastically reduced in the BDL cirrhotic rats (Fig. 3B). To confirm successful transduction into liver and proper expression of the antisense we performed PCR allowing the amplification of a 225-bp fusion containing sequences specific for TGF- $\beta 1$ and the SV40-polyadenylation signal (Fig. 3C). We next tested whether Ad5-CMVAS-TGF- $\beta 1$ infection was able to suppress liver fibrogenesis in BDL-treated rats. Therefore, we first quantified the static levels of collagen by Sirius red staining (Fig. 4). Impressively, the deposition of fibrillar collagen was substantially decreased in response to administration of the antisense. This inhibitory effect was observed in all areas of the liver, with no significant difference noticed between the different lobules (not shown) while no reduction in fibrosis was observed in Ad5-CMV-EGFP-treated rats. Also the tendency for proliferation of biliary ductules in portal areas was significantly reduced in injured livers expressing the antisense (compare Figs. $4 \mathrm{C}$ and $4 \mathrm{E}$ ). The morphological evaluation of representative liver sections by two independent pathologists revealed fibrosis scores with increasing severity ranging from 0 (no BDL, saline), 1 (BDL, Ad5-CMV-AS-TGF- $\beta 1$ ), and 3 (BDL, Ad5-CMVEGFP), respectively. Additionally, we demonstrate the antifibrotic capacity of the transgene by its inhibitory effects on $\alpha$-SMA expression. In livers of BDL-treated rats, the immunoreactivity for $\alpha$-SMA as assessed by immunohistochemistry was significantly reduced by treatment with the TGF- $\beta 1$ antisense construct (Figs. 5A, 5B,5C,5D). To confirm and demonstrate the lowering in $\alpha$-SMA expression more quantitatively, we further performed western blot analysis showing strong suppression of $\alpha$ SMA in animals treated with the transgene (Fig. 5E).
Again, these results indicate that Ad5-CMV-AS-TGF- $\beta 1$ specifically inhibits ongoing fibrosis in liver.

In previous reports, the elimination of TGF- $\beta$ signaling by adenovirus-mediated local expression of a dominant-negative type II TGF- $\beta$ receptor in the liver of rats treated with dimethylnitrosamine was associated with serum levels of liver specific transaminases comparable to normal controls [11]. When we measured AST and ALT in the serum of sacrificed rats which received BDL and gene transfer, the levels of these hepatic enzymes were the same regardless of whether the BDL-treated rats were infused with saline, Ad5-CMV-EGFP, or Ad5-CMV-AS-TGF- $\beta 1$ indicating that the hepatic injury induced by BDL per se is not influenced by TGF- $\beta$ under the chosen experimental conditions.

\section{Discussion}

In liver fibrogenesis TGF- $\beta$ is the most potent profibrogenic signaling factor triggering expression, accumulation and deposition of collagen [30]. Elevated levels of TGF- $\beta$ are associated with altered lobular organisation, increase of hepatocyte turnover and apoptosis [7-9]. Therefore, mechanisms antagonizing TGF- $\beta$ function or blocking TGF- $\beta$ synthesis are primary targets for directing antifibrotic therapies. In this view several approaches were identified to abolish TGF- $\beta$ signaling. These include administration of antioxidants, specific drugs, herbal compounds, neutralizing antibodies, TGF- $\beta$ binding proteins (scavengers), antagonistic cytokines, suppressors of apoptosis, or specifically designed oligonucleotides [2]. Another promising approach is the inhibition of proteolytic release and activation of latent TGF- $\beta$. Representative, the serine protease inhibitor camostat mesilate was recently found to suppress HSC activation by inhibiting hepatic plasmin activity and thereby preventing hepatic fibrosis [31]. Presently, potential gene therapies using dominant negative or soluble T $\beta \mathrm{R}$-II are under close investigation. Because T $\beta \mathrm{R}-\mathrm{II}$ is the primary binding receptor for TGF- $\beta$, overexpression of an inactive T $\beta$ R-II construct counters TGF- $\beta$ actions. The development of hepatic fibrosis by dimethylnitrosamine (DMN) in rats was markedly reduced by adenoviral vectors expressing either a truncated human T $\beta$ R-II injected via the portal vein [11] or soluble human TGF- $\beta$ receptors (a chimeric protein between an entire ectodomain of human T $\beta$ R-II and the Fc portion of human immunoglobulin $\mathrm{G}$ ) injected intramuscularly [13]. Impressively, a single injection of adenovirus expressing the truncated receptor, given prior to DMN administration, appeared to prevent both hepatic injury and the development of hepatic fibrosis. In a subsequent study, the same adenoviral vector was administered to animals with ongoing fibrosis after 3 weeks of DMN in order to determine whether reversal of fibrosis occurs with this agent. The results were similar with lack of 


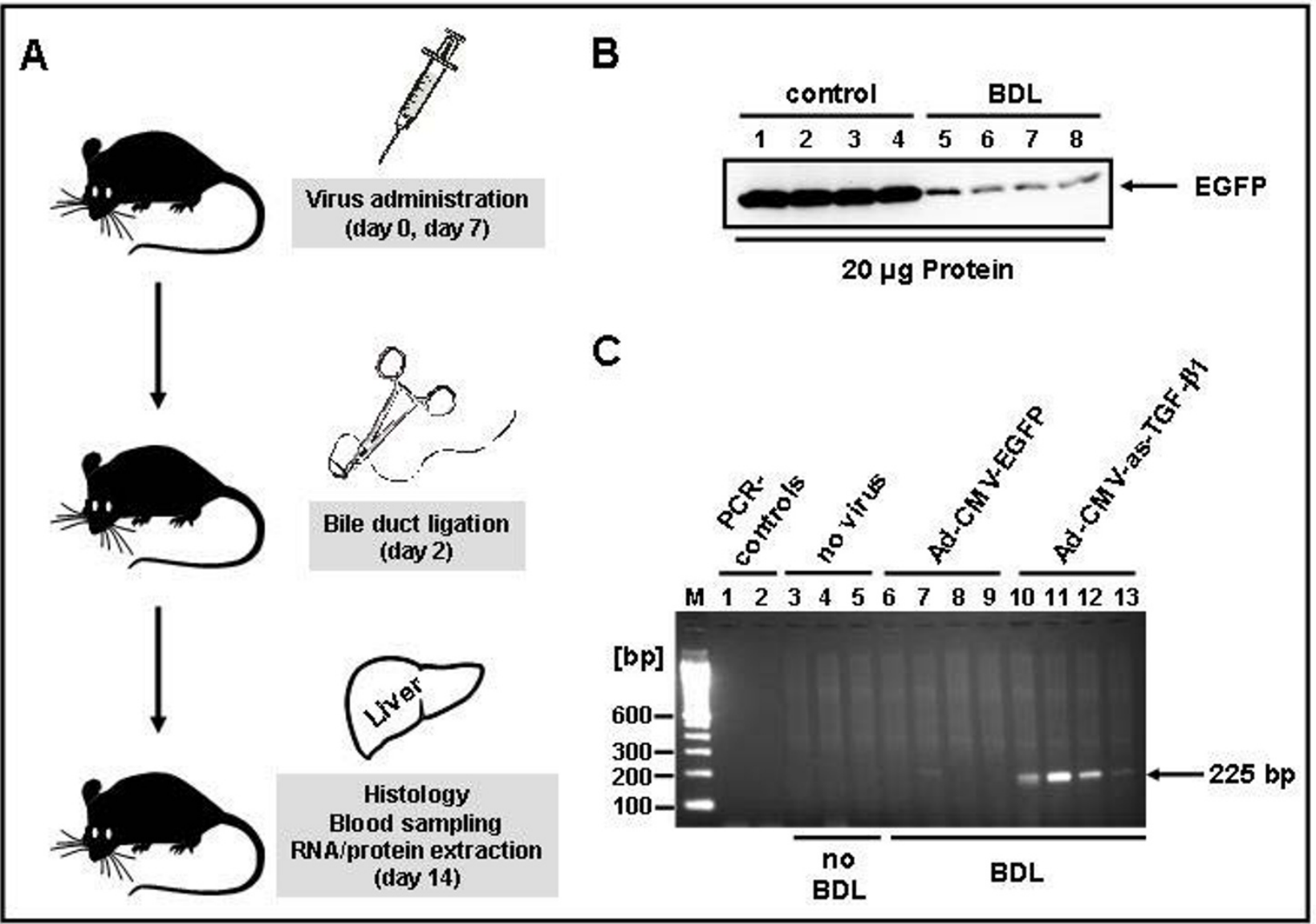

Figure 3

Time course for experimental testing of antifibrotic devices directed against TGF- $\beta$. (A) Male Sprague-Dawley rats were given a single infusion of either Ad5-CMV-AS-TGF- $\beta$ I, Ad5-CMV-EGFP, or phosphate buffered saline at day 0 and a replenishment infusion at day 7 . Two days after the first injection, the animals were subjected to bile duct ligation (BDL). At day 12, animals were sacrificed for liver histology and sampling of protein and RNA specimens. (B) Transfer of adenoviruses into normal and injured livers. A reporter adenovirus expressing the green fluorescent protein (EGFP) was injected two days prior surgery via the tail vein. Four days after surgery, the livers were homogenized, and $20 \mu g$ of protein samples each were tested for expression of EGFP by Western blot analysis. Note the lower level of transgene expression in animals that received bile duct ligature. (C) Transduction of AS-TGF- $\beta$ I in normal and injured livers in vivo. Liver injury was induced by BDL and adenoviruses $\left(I \times 10^{10} \mathrm{pfu} / \mathrm{kg}\right)$ were administered to normal or injured rats two days prior BDL. Liver samples were analyzed for expression of the transgene by RT-PCR.

progression and possibly some regression of hepatic fibrosis in rats that received the dominant negative receptor [12]. The antifibrogenic potential of soluble T $\beta$ R-II was also demonstrated in the rat bile duct ligature model by slow infusion of the chimeric proteins into the femoral vein [32]. Another option to inhibit TGF- $\beta$ function is to interfere with postreceptor signaling. Overexpression of Smad7, a natural antagonist of TGF- $\beta$ signaling, prevents bleomycin induced pulmonary fibrosis in mice [16] and was recently shown to prevent activation of hepatic stellate cells and liver fibrosis in rats [33].

The present work evaluates the potency of an antisense mRNA complementary to the 3 ' coding sequence of TGF$\beta 1$ in preventing liver fibrogenesis during obstructive bile duct ligature in rat. The efficacy of the expressed antisense 

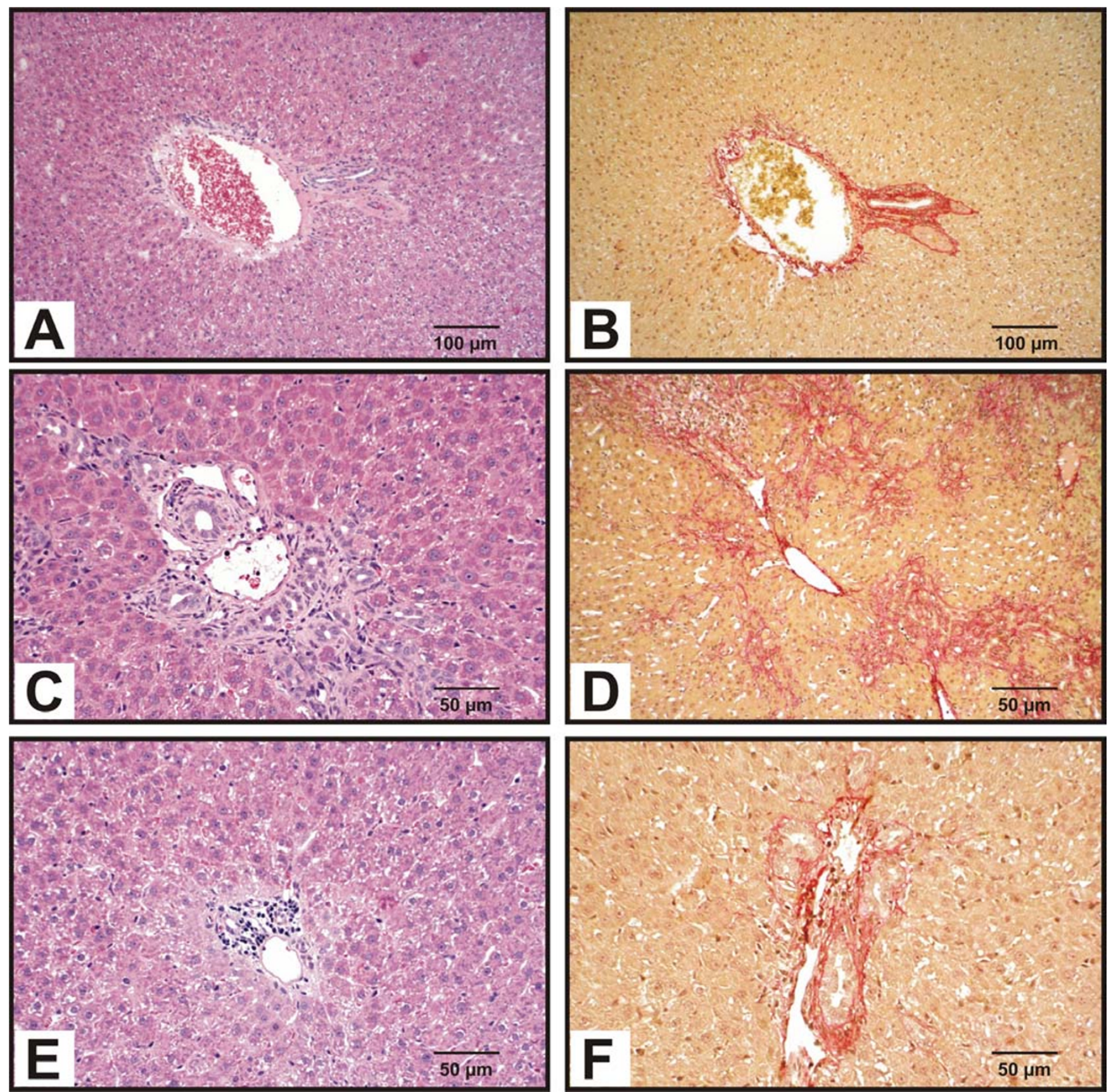

Figure 4

Histology of livers from rats subjected to BDL. Rats were infused via the tail vein with saline (A, B), Ad5-CMV-EGFP (C, D), or Ad5-CMV-AS-TGF- $\beta$ I (E, F). The animalswere subjected to BDL (C-F) or were sham-operated (A, B) according to the time course outlined in Fig. 3A. Liver sections were examined histologically by hematoxylin (A, C, E) or Sirius red (B, D, F) staining. Note the fibrous expansion of portal areas with occasional portal to portal bridging in (D) and reduced fibrosis showing only marginal fibrous expansion in the portal areas without septa in (F). Original magnifications are $\times 100(\mathbf{A}, \mathbf{B})$ and $\times 200$ (C-F). 


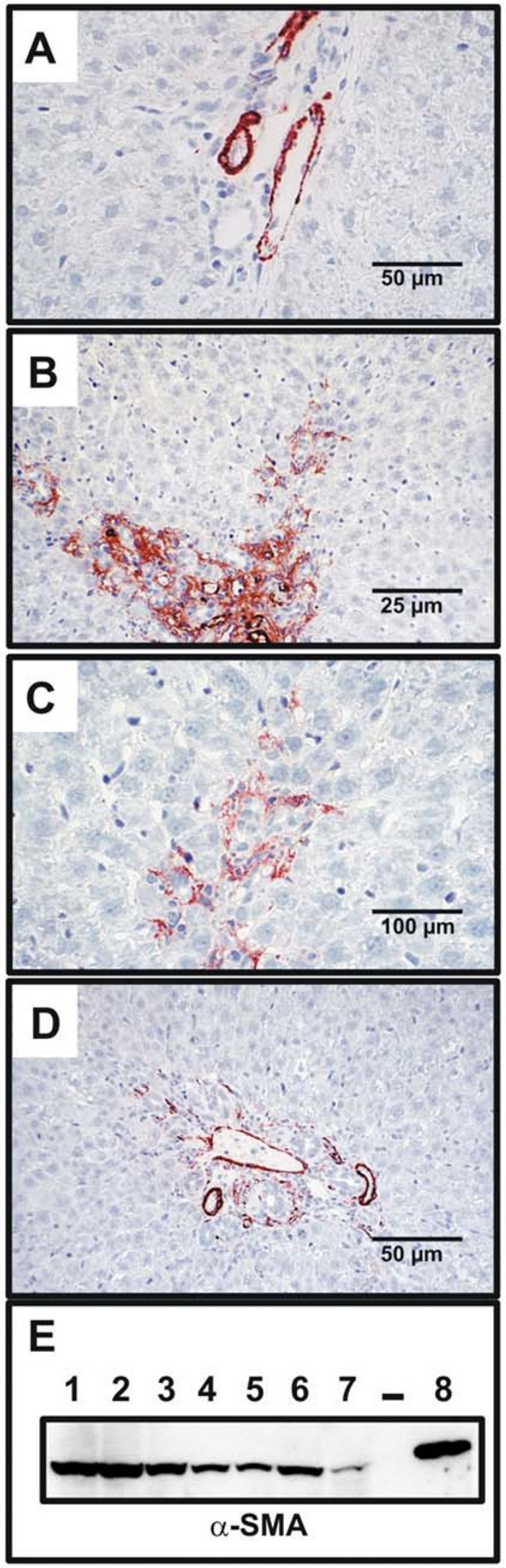

\section{Figure 5}

$\alpha$-SMA expression in liver. Rats were treated as described in the legend to Fig. 3. (A) In normal livers, $\alpha$-SMA positivity was noted in smooth muscle cells of portal tract vessels and in a few cells surrounding terminal hepatic venules. $(\mathbf{B}, \mathbf{C})$ In $B D L$ animals infected with the control virus (Ad5-CMV-EGFP), livers were highly enriched in $\alpha$ SMA-positive HSC forming layers around the bile ductules. In addition, $\alpha$-SMA positive cells in the periportal sinusoids were visible in the vicinity of ductular areas, consistent with the active recruitment of activated HSC by ductular structures.(D) BDL animals infected with Ad5-CMV-AS-TGF- $\beta$ I showed no significant increase in $\alpha$-SMA staining. (E) Immunoblot analysis of $\alpha$-SMA expression in livers of BDL rats ( 1 3), BDL rats infected with Ad5-CMV-AS-TGF- $\beta$ I (4-6), or normal control rats (7). As a positive control a total lysate from culture-activated HSC expressing high levels of the 42kD $\alpha$-SMA was loaded (8). Original magnifications are $\times 200$ (A, D), $\times 100$ (B), and $\times 400$ (C), respectively.

to block TGF- $\beta$ synthesis in culture-activated HSC was previously shown by immunoprecipitation, Western blot, quantitative TGF- $\beta 1$ ELISA, and cell proliferation assays [17]. We here demonstrate that the in vitro synthesized quantities of the expressed transgene delivered by an adenoviral vector exceed endogenous levels of TGF- $\beta 1$ mRNAs by several orders of magnitude. To verify the efficacy of the antisense we determined collagen and $\alpha$-SMA as markers in an experimental in vivo model of liver fibrogenesis. In this experimental model of obstructive hepatic injury, damage was induced by ligature of the common bile duct leading to a drastic accumulation of collagen content in the liver. Delivery of the antisense complementary to TGF- $\beta 1$ mRNA prevented the deposition of collagen as assessed by histochemistry using Sirius red staining. Further, in animals receiving the transgene, we found also reduced expression of $\alpha$-SMA in histological sections and protein extracts analyzed by western blot. Previous studies examined the role of TGF- $\beta$ inhibition on hepatic fibrogenesis induced by bile duct ligation, using soluble T $\beta$ RII constructs sequestering TGF- $\beta$. In one report it was demonstrated that the soluble receptor was able to reduce collagen and $\alpha$-SMA quantities when given at the time of injury or given at day 4 after injury [32]. The authors concluded that soluble TGF- $\beta$ receptor is an effective inhibitor in vivo and merits clinical evaluation as a novel agent for controlling hepatic fibrosis in chronic liver injury [32]. However, the chimeric fusion consisting of the extracellular domain of T $\beta$ RII with the Fc portion of an immunoglobulin might create potent epitopes and thereby preventing its repetitive application for longer time periods. Therefore, the finding that an antisense complementary to endogenous TGF- $\beta 1$ mRNA has the 
same beneficial antifibrotic capacity may offer considerable promise to alleviate TGF- $\beta$ induced damages during chronic liver diseases and increase the safety of future intervention strategies by diminishing the risk of avoidable immune responses.

However, we have not yet analyzed the consequences of long-term systemic exposure to the TGF- $\beta$ antisense, particular in regard to systemic effects like body weight, deterioration of a clinical status, or the likelihood of increased spontaneous tumorigenesis and immune system dysfunctions. Moreover, we have no estimation of how much active TGF- $\beta$ is still present in liver cells of Ad5CMV-AS-TGF- $\beta 1$-infected animals. Complementary future studies are necessary to address these critical issues.

\section{Conclusions}

We conclude that our data gives strong evidence that the transfer of the designed TGF- $\beta 1$ antisense is sufficient to specifically abolish the diverse effects of TGF- $\beta$ in ongoing hepatic fibrogenesis. Therefore, the antisense strategy is attractive as a therapeutic agent for preventing stellate cell activation and may help clarify the role of TGF- $\beta$ in this process both in vitro and in vivo. Moreover, the antisense technology may provide opportunities for the treatment of chronic liver diseases.

\section{List of abbreviations}

Ad5: adenovirus serotype 5,

ALT: alanine aminotransferase,

AS: antisense,

$\alpha$-SMA: $\alpha$-smooth muscle actin,

AST: aspartate aminotransferase,

BDL: bile duct ligature,

bp: base pair(s),

DMEM: Dulbecco's modified Eagle medium,

FCS: fetal calf serum,

GAPDH: glyceraldehyde-3-phosphate dehydrogenase,

EGFP: enhanced green fluorescent protein,

HBSS: Hanks buffered standard saline,

HSC: hepatic stellate cell(s),

MFB: myofibroblast(s),
PCR: polymerase chain reaction,

TGF- $\beta 1$ : transforming growth factor- $\beta 1$.

\section{Competing interests \\ None declared.}

\section{Acknowledgements}

This work was supported in part by grants from the Federal Ministry of Education and Research of Germany (BMBF, IZKF Biomat) and Aachen University (START project Identification of Molecular Markers and Gene Therapy of Fibrosis and Wound Healing) to RW. We thank H. P. Fischer and C. Esch for help with the immunohistochemistry.

\section{Authors' contributions}

MA, JT, and NJ carried out the molecular studies. SSL carried out all surgeries (bile duct ligation, administration of adenoviruses). IT and RB performed the histological scoring of tissue sections. AMG and RW participated in the design and coordination of the study. All authors read and approved the final manuscript.

\section{References}

I. Moustakas A, Pardali K, Gaal A and Heldin CH: Mechanisms of TGF- $\beta$ signalling in regulation of cell growth and differentiation. Immunol Lett 2002, 82:85-91.

2. Gressner AM, Weiskirchen R, Breitkopf $K$ and Dooley S: Roles of TGF- $\beta$ in hepatic fibrosis. Front Biosci 2002, 7:D793-D807.

3. Friedman SL: Molecular regulation of hepatic fibrosis, an integrated cellular response to tissue injury. J Biol Chem 2000, 275:2247-2250.

4. Heldin $\mathrm{CH}$, Miyazono $\mathrm{K}$ and ten Dijke P: TGF- $\beta$ signalling from cell membrane to nucleus through SMAD proteins. Nature 1997, 390:465-471.

5. Piek E, Heldin $\mathrm{CH}$ and ten Dijke P: Specificity, diversity, and regulation in TGF-beta superfamily signaling. FASEB J 1999, 13:2105-2124.

6. Miyazono K, ten Dijke $P$ and Heldin CH: TGF- $\beta$ signalling by Smad proteins. Adv Immunol 2000, 75: I I5- 157.

7. Sanderson N, Factor V, Nagy P, Kopp J, Kondaiah P, Wakefield L, Roberts $A B$, Sporn MB and Thorgeirsson SS: Hepatic expression of mature transforming growth factor beta $I$ in transgenic mice results in multiple tissue lesions. Proc Natl Acad Sci USA 1995, 92:2572-2576.

8. Clouthier DE, Comerford SA and Hammer RE: Hepatic fibrosis, glomerulosclerosis, and a lipodystrophy-like sindrome in PEPCK-TGF- $\beta$ I transgenic mice. J Clin Invest 1997, 100:2697-27I3.

9. Kanzler S, Lohse AW, Keil A, Henninger J, Dienes HP, Schirmacher P, Rose-John S, zum Buschenfelde $\mathrm{KH}$ and Blessing M: TGF-beta I in liver fibrosis: an inducible transgenic mouse model to study liver fibrogenesis. Amer J Physiol 1999, 276:G I059-GI 068.

10. Komesli S, Vivien D and Dutartre P: Chimeric extracellular domain of type II transforming growth factor (TGF)- $\beta$ receptor fused to the Fc region of human immunoglobulin as a TGF- $\beta$ antagonist. Eur J Biochem 1998, 254:505-5I3.

II. Qi Z, Atsuchi N, Ooshima A, Takeshita A and Ueno H: Blockade of type $\beta$ transforming growth factor signaling prevents liver fibrosis and dysfunction in the rat. Proc Natl Acad Sci USA 1999, 96:2345-2349.

12. Nakamura T, Sakata R, Ueno T, Sata $M$ and Ueno $H$ : Inhibition of transforming growth factor $\beta$ prevents progression of liver fibrosis and enhances hepatocyte regeneration in dimethylnitrosamine-treated rats. Hepatology 2000, 32:247-255.

13. Ueno H, Sakamoto T, Nakamura T, Qi Z, Astuchi N, Takeshita A, Shimizu $\mathrm{K}$ and Ohashi $\mathrm{H}$ : A soluble transforming growth factor 
$\beta$ receptor expressed in muscle prevents liver fibrogenesis and dysfunction in rats. Hum Gene Ther 2000, II:33-42.

14. Isaka $Y$, Tsujie $M$, Ando $Y, N a k a m u r a ~ H$, Kaneda $Y$, Imai $E$ and Hori $M$ : Transforming growth factor- $\beta I$ antisense oligodeoxynucleotides block interstitial fibrosis in unilateral ureteral obstruction. Kidney Int 2000, 58: I885- I 892.

15. Merrilees M, Beaumont B, Scott L, Hermanutz $V$ and Fennessy $P$ : Effects of TGF- $\beta$ (I) antisense S-oligonucleotide on synthesis and accumulation of matrix proteoglycans in balloon catheter-injury neointima of rabbit carotid arteries. J Vasc Res 2000 37:50-60.

16. Nakao A, Fujii M, Matsumura R, Kumano K, Saito Y, Miyazono K and Iwamoto I: Transient gene transfer and expression of Smad7 prevents bleomycin-induced lung fibrosis in mice. J Clin Invest 1999, 104:5-II.

17. Arias M, Lahme B, Van de Leur E, Gressner AM and Weiskirchen R: Adenoviral delivery of an antisense RNA complementary to the $3^{\prime}$ coding sequence of transforming growth factor- $\beta$ I inhibits fibrogenic activities of hepatic stellate cells. Cell Growth Differ 2002, 13:265-273.

18. de Leeuw AM, McCarthy SP, Geerts A and Knook DL: Purified rat liver fat-storing cells in culture divide and contain collagen. Hepatology 1984, 4:392-403.

19. Fehrenbach $\mathrm{H}$, Weiskirchen $\mathrm{R}$, Kasper $M$ and Gressner AM: Up regulated expression of the receptor for advanced glycation end products in cultured rat hepatic stellate cells during transdifferentiation to myofibroblasts. Hepatology 200I, 34:943-952.

20. Schafer $S$, Zerbe $O$ and Gressner AM: The synthesis of proteoglycans in fat-storing cells of rat liver. Hepatology 1987, 7:680-687.

21. Gressner AM and Zerbe O: Kupffer cell-mediated induction of synthesis and secretion of proteoglycans by rat liver fat-storing cells in culture. J Hepatol 1987, 5:299-310.

22. Weiskirchen R, Kneifel J, Weiskirchen S, van de Leur E, Kunz D and Gressner AM: Comparative evaluation of gene delivery devices in primary cultures of rat hepatic stellate cells and rat myofibroblasts. BMC Cell Biol 2000, I:4.

23. Brunt EM: Grading and staging the histopathological lesions of chronic hepatitis: the Knodell histology activity index and beyond. Hepatology 2000, 31:24I-246.

24. Lopez-De Leon A and Rojkind M: A simple micromethod for collagen and total protein determination in formalin-fixed paraffin-embedded sections. J Histochem Cytochem 1985, 33:737-743.

25. Accatino L, Contreras A, Fernandez S and Quintana C: The effect of complete biliary obstruction on bile flow and bile acid excretion: postcholestatic choleresis in the rat. J Lab Clin Med 1979, 93:706-7|7.

26. Accatino L, Contreras A, Berdichevsky E and Quintana C: The effect of complete biliary obstruction on bile secretion. Studies on the mechanisms of postcholestatic choleresis in the rat. J Lab Clin Med 198I, 97:525-534.

27. Kountouras J, Billing $\mathrm{BH}$ and Scheuer PJ: Prolonged bile duct obstruction: a new experimental model for cirrhosis in the rat. Br J Exp Pathol 1984, 65:305-3 II.

28. $\mathrm{Yu}$ Q, Que LG and Rockey DC: Adenovirus-mediated gene transfer to nonparenchymal cells in normal and injured liver. Am J Physiol Gastrointest Liver Physiol 2002, 282:G565-G572.

29. Yu Q, Shao R, Qian HS, George SE and Rockey DC: Gene transfer of the neuronal NO synthase isoform to cirrhotic rat liver ameliorates portal hypertension. J Clin Invest 2000, 105:74I-748.

30. Garcia-Trevijano ER, Iraburu MJ, Fontana L, José A, DominguezRosales JA, Auster A, Covarrubias-Pinedo A and Rojkind M: Transforming growth factor $\beta I$ induces the expression of a $\alpha I$ (I) procollagen mRNA by a hydrogen peroxide-C/EBP $\beta$ dependent mechanism in rat hepatic stellate cells. Hepatology 1999, 29:960-970.

31. Okuno M, Akita K, Moriwaki H, Kawada N, Ikeda K, Kaneda K, Suzuki $Y$ and Kojima S: Prevention of rat hepatic fibrosis by the protease inhibitor, camostat mesilate, via reduced generation of active TGF- $\beta$. Gastroenterology 200I, I 20: | 784- |800.

32. George J, Roulot D, Koteliansky VE and Bissell DM: In vivo inhibition of rat stellate cell activation by soluble transforming growth factor beta type II receptor: A potential new therapy for hepatic fibrosis. Proc Natl Acad Sci USA 1999, 96: I 27 I9- 12724.

33. Dooley S, Hamzavi J, Breitkopf K, Wiercinska E, Said HM, Lorenzen J, ten Dijke $P$ and Gressner AM: Smad7 prevents activation of hepatic stellate cells and liver fibrosis in rats. Gastroenterology 2003, I25:|78-19|.

\section{Pre-publication history}

The pre-publication history for this paper can be accessed here:

http://www.biomedcentral.com/1471-230X/3/29/pre pub
Publish with Biomed Central and every scientist can read your work free of charge

"BioMed Central will be the most significant development for disseminating the results of biomedical research in our lifetime. "

Sir Paul Nurse, Cancer Research UK

Your research papers will be:

- available free of charge to the entire biomedical community

- peer reviewed and published immediately upon acceptance

- cited in PubMed and archived on PubMed Central

- yours - you keep the copyright 